㣢最CEIVED JNS 242000 OSTI

\section{All-solid-state optical pulse shaper for the OMEGA laser fusion facility}

\author{
A. V. Okishev, M. D. Skeldon, R. L. Keck, and W. Seka \\ Laboratory for Laser Energetics, University of Rochester \\ 250 East River Road, Rochesser, NY 14623 \\ Phone: 716275.5101 \\ Fax:716/275-5960 \\ e-mail: aoki@ lle.rochester.edu
}

\title{
Introduction
}

An integral part of the contemporary high-power laser system for inertial confinement fusion (ICF) research is a flexible pulse-shaping system that is able to produce a laser pulse temporal profile specified in advance and controlled to a high degree of accuracy. Temporally shaped optical pulses can be produced by applying shaped electrical waveforms to an integrated-optics (10) modulator [1,2]. These shaped electrical waveforms are sent to the optical modulator synchronized with the passage through the modulator of a flat-top optical pulse from a singlefrequency laser. The optical pulse exiting the modulator is then shaped in accordance with the voltage-dependent transfer function of the modulator. A pulse-shaping system has been in operation on OMEGA for several years [3]. Recently the performance of this pulse-shaping system was significantly improved by replacing the flash-lamppumped single-frequency laser with a diode-pumped, computer-controlled master oscillator [4]. Currently the pulseshaping system uses an electrical-waveform generator based on the reflection of an electrical square pulse from a variable-impedance microstrip line. The electrical square pulse is generated by using a charge line with $\mathrm{Si}$ photoconductive switches activated by a single pulse from a laser system. The laser system includes a mode-locked cW timing laser, regenerative amplifier, SBS pulse compressor, and laser amplifiers. The complexity of this laser system motivated us to develop a simplified pulse-shaping system that meets all the pulse-shaping requirements for the OMEGA laser. This system includes a highly stable diode-pumped single-frequency master oscillator, a diodepumped preamplifier, aperture-coupled striplines (ACSL), and commercially available electrical square-pulse generators, which make it a completely solid-state computer-controlled system.

All-solid-state pulse shaper

The block diagram of the new OMEGA optical pulse shaper is shown in Fig. 1. The diode-pumped single-frequency

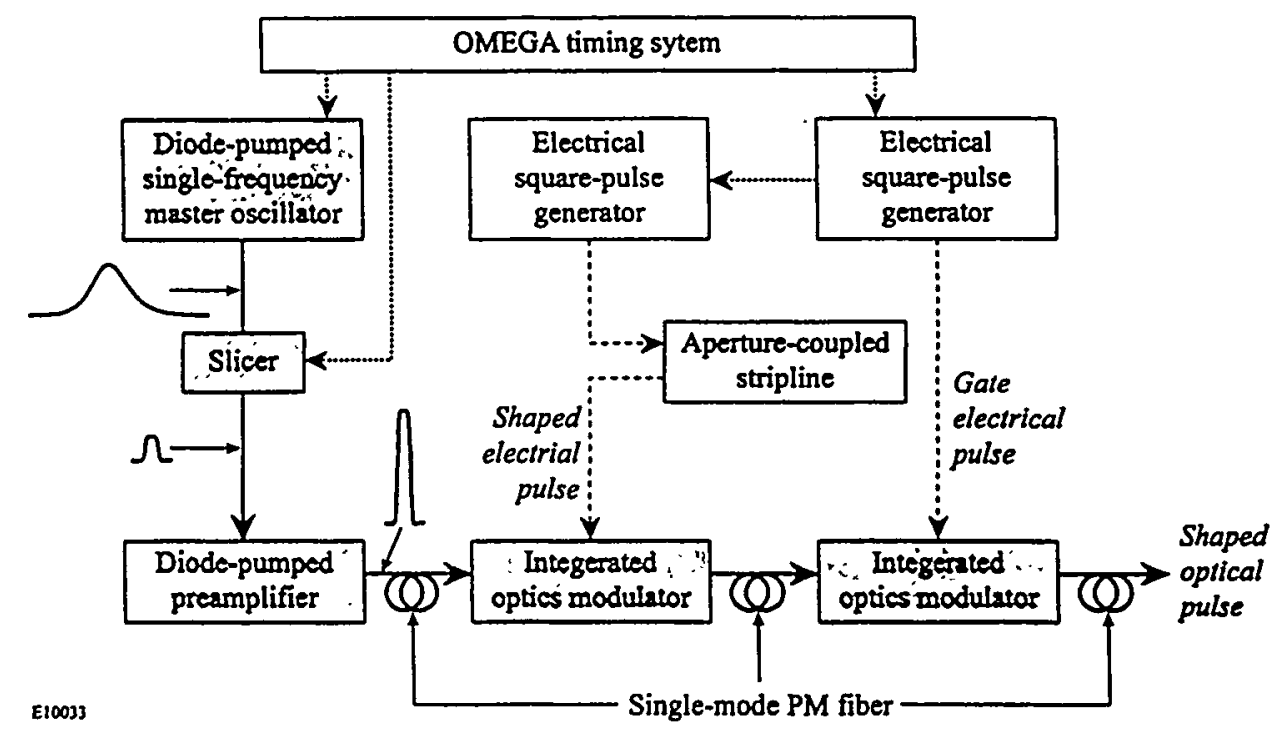

Fig. 1. All-solid-state pulse shaper for the OMEGA laser system. A single-frequency sliced and amplified pulse from the master oscillator is shaped with a modulator driven by the aperture-coupled stripline electrical waveform generator and gated with a modulator driven by a square-pulse generator. 


\section{DISCLAIMER}

This report was prepared as an account of work sponsored by an agency of the United States Government. Neither the United States Government nor any agency thereof, nor any of their employees, make any warranty, express or implied, or assumes any legal liability or responsibility for the accuracy, completeness, or usefulness of any information, apparatus, product, or process disclosed, or represents that its use would not infringe privately owned rights. Reference herein to any specific commercial product, process, or service by trade name, trademark, manufacturer, or otherwise does not necessarily constitute or imply its endorsement, recommendation, or favoring by the United States Government or any agency thereof. The views and opinions of authors expressed herein do not necessarily state or reflect those of the United States Government or any agency thereof. 


\section{DISCLAIMER}

Portions of this document may be illegible in electronic image products. Images are produced from the best available original document. 
master oscillator [4] produces highly stable, 150-ns, $Q$-switched laser pulses at $300-\mathrm{Hz}$ repetition rate. A tigh repetition rate allows us to use a high-bandwidth sampling oscilloscope for the pulse-shape measurement, which provides a higher temporal resolution than a single-shot digital oscilloscope. The flat-top portion of the master oscillator's 150-ns output pulse is used for pulse shaping. A high-rep-rate slicer produces a 20-ns flat-top pulse from the 150-ns pulse, which eliminates unused energy from the pulse to avoid generating stimulated Brillouin scattering in our single-mode fiber. The diode-pumped preamplifier boosts the flat-top pulse energy ten times to meet OMEGA pulse-shaping energy requirements (200 nJ per channel). The amplified pulse is launched into a single-mode, polarization-maintaining (PM) fiber, split into four fiber channels, and sent to the IO pulse-shaping modulators. Each pulse-shaping channel consists of two modulators: one shapes the optical pulse, and the other gates the shaped pulse, improving the overall bandwidth and contrast of the pulse. The output shaped optical pulse is sent via singlemode PM fiber to a regenerative amplifier and then to the OMEGA laser system for amplification and frequency conversion.

\section{ACSL-based electrical waveform generator}

The optical pulse exiting the modulator is shaped in accordance with the voltage-dependent transfer function of the modulator. Hence, the electrical-waveform generator is an important component in any optical-pulse-shaping system incorporating optical modulators.

A square electrical waveform from a commercially available pulse generator is sent to the ACSL [5]. The ACSL generates a shaped electrical waveform that is sent directly to the IO modulator for pulse shaping (Fig. 1). An ACSL is a four-port device consisting of two $50-\Omega$ striplines separated by a ground plane with an aperture to provide directional coupling as shown in Fig. 2. A square pulse propagating along one of the two $50-\Omega$ striplines is coupled to the other stripline in the backward direction. Knowing the electrical coupling coefficient as a function of the aperture width, the ACSL model determines the exact aperture shape to be machined to generate the required electrical waveform.

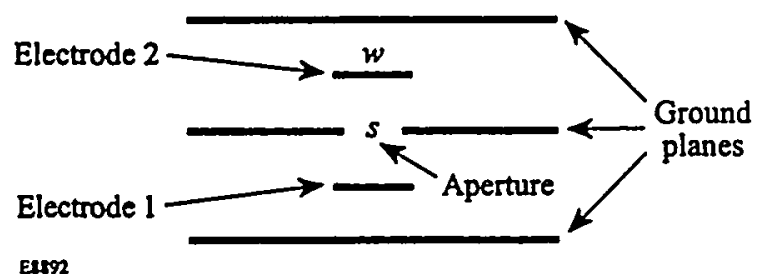

Fig. 2. Cross-sectional view of an ACSL in the coupling region. The electrical width $w$ is chosen to provide a $50-\Omega$ impedance structure. The amount of electrical coupling from electrode 1 to electrode 2 depends on the aperture width s.

Pulse shaper performance

The temporal profile of the shaped pulse, when amplified and frequency tripled by the OMEGA laser system, must compensate for the temporal distortions caused by gain saturation in the amplifiers and by the frequency-tripling process, and will produce the desired pulse shape on target. Figure 3 shows the IO modulator output pulse shape required to produce a reversed ramp UV pulse on target. Good agreement is seen between the measured pulse shape and the design shape.

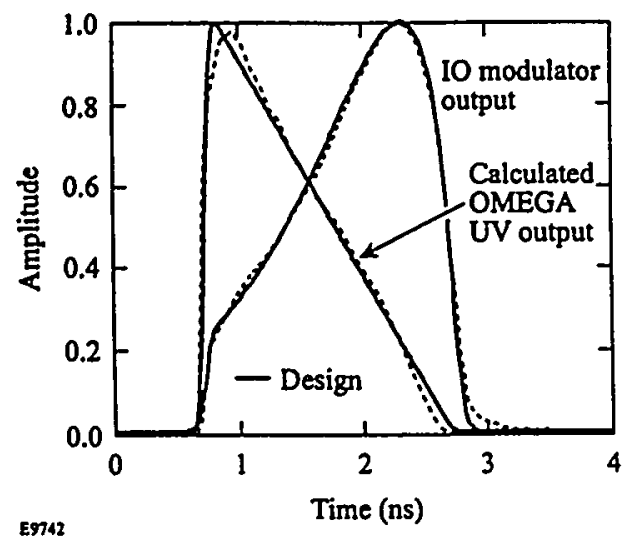

Fig. 3. The OMEGA pulse shaper is able to produce precisely the tailored optical waveforms (reversed ramp pulse shape is shown). 


\section{Conclusion}

We have developed an all-solid-state, compact, computer-controlled, flexible optical pulse shaper for the OMEGA laser facility. This pulse shaper produces high bandwidth, temporally shaped laser pulses that meet OMEGA requirements. The design is a significant simplification over existing technology with improved performance capabilities.

\section{Acknowledgment}

This work was supported by the U.S. Department of Energy Office of Inertial Confinement Fusion under Cooperative Agreement No. DE-FC03-92SF19460, the University of Rochester, and the New York State Energy Research and Development Authority. The support of DOE does not constitute an endorsement by DOE of the views expressed in this article.

\section{References}

(1] R. B. Wilcox, "Pulse shaping with transmission lines," U. S. patent No. 4,667,161 (19 May 1987).

[2] R. B. Wilcox, W. Bebrends, D. F. Browning, D. R. Speck, and B. M. Van Wontergem, "Fussion leser oscillator and pulse-forming system using integrated optics," in Laser Coherence Control: Technology and Applications, ediled by H. T. Powell and T. J. Kessier (SPIE, Bellingham, WA, 1993), Vol. 1870, pp. 53-63.

[3] A. V. Okishev, M. D. Skeldon, S. A. Letzring, W. R. Donaldson, A. Babushkin, and W. Seka, The pulse-shaping system for the 60-beam, $30 . k J$ (UV) OMEGA laser," in Superintense Laser Fields, edited by A. A. Andreev and V. M. Gordienko (SPIE, Bellingham, WA, 1996), Vol, 2770, pp. 10-17.

[4] A. V. Okishev, M. D. Skeldon, and W. Seka, "A highiy stable, diode-pumped master oscillator for the OMEGA laser facility." in OSA TOPS on Advanced Solld-State Lasers, edited by M. M. Fejer, H. Injeyan, and U. Kelles (Optical Society of America, Washington, D.C., 1999). Vol. 26, pp. 228-235.

[5] M. D. Skeldon, A. V. Okishev, R. L. Keck, S. A. Letzring, and W. Seka, "An optical pulse-shaping system based on apertire-coupled striplines for OMEGA pulse shaping applications," in Solid State Lasers for Application to Inertial Confinement Fusion, edited by W. H. Lowdermilk (SPEE, Bellingham, WA, 1999), Vol. 3492, pp. 131-135. 